\title{
Sustainability and change in the institutionalized commute in Belgium: exploring regional differences
}

\author{
Applied Geography
}

Sébastien Dujardin ${ }^{1}$, Kobe Boussauw ${ }^{2}$, Florence Brévers ${ }^{1}$, Jean-Marc

Lambotte $^{1}$, Jacques Teller ${ }^{1}$, Frank Witlox ${ }^{2}$

1. Lepur - Research Centre on Territorial, Urban and Rural Sciences, University of

Liège, Liège, Belgium

2. Geography Department, Ghent University, Ghent, Belgium

Corresponding author: sebastien.dujardin@fundp.ac.be, rue de Bruxelles 61, B-5000 Namur, Belgique

This paper examines regional differences in commute-energy performance in Belgium, and explores their relationships with spatial characteristics such as the distribution of population and housing, the metropolitan influence of the Brussels agglomeration, and the compactness of cities and towns. We also investigate contradictions between Belgian state-wide commute policy and regional differences in average commuting distance and mode choice. Against a background of long-term federal measures that traditionally encourage longdistance commuting in Belgium, we find striking discrepancies between the structure and the development of commuting patterns in the three administrative regions of Flanders, Wallonia and Brussels. Residents of Brussels show the most sustainable commuting patterns, due to the metropolitan spatial structure. Residents of Wallonia represent the least sustainable commute. Given the rather weak regional economy of Wallonia compared with Flanders, commuters must frequently seek employment far from their residence. Population changes and consequent developments in the housing market seem to exacerbate this competitive disadvantage, since most growth occurs in relatively remote rural areas that are nevertheless within reach of the main employment centres.

Keywords: sustainable commuting, regional planning, Belgium 


\section{Introduction}

Following the energy crisis in the 1970s, countries around the world including Belgium prioritized reductions in oil dependency through improved energy efficiency. In the 1990s, the broader concept of sustainability through energy efficiency was placed higher on the agenda to reach climate change targets (Blanco et al., 2009). These deliberations have received increased impetus by successive surges in the crude oil price in 2008 and 2012. Today, reducing energy consumption remains at the top of a number of political agendas for two main reasons: (1) greenhouse gas (GHG) emissions from human activities have been proven to cause global warming (Davoudi et al., 2009; IPCC, 2007), and (2) the failure of oil production to meet demand, commonly known as "peak oil" is expected to occur within the next decades (Aleklett et al., 2010; IEA, 2010). Climate change and peak oil issues are bound to have far-reaching consequences for the economy in general, and for the transport sector and mobility levels in particular.

However, these observed tendencies are not in line with current energy saving targets. In most developed countries, levels of mobility have increased substantially in the recent past because of a rapid decline in transport costs combined with an increase in travel speed (Ewing, 1994), while fuel efficiency per motor vehicle has improved only to a limited extent (De Vlieger et al., 2006). The increase in mobility levels has allowed dispersed regional development to continue along with an overall growth in fuel consumption and carbon emissions by motorized transport. Everyday travel mostly relies on fossil fuels and is increasingly dependent on the automobile (Banister, 2005), while the worldwide oil dependence rate of the global transport sector is about $95 \%$ (IEA, 2010).

In terms of emissions, transport accounts for about $14 \%$ of GHG emissions worldwide (World Resource Institute, 2009), a percentage that is even higher in 
industrialized countries. In Belgium for instance, the share of overland transport represents $20 \%$ of total GHG emissions (CNC, 2010). In this context, monitoring and analysing changes in travel behaviour are becoming increasingly crucial in anticipating and adapting to possible rapid change and an uncertain future.

One of the main factors influencing general travel behaviour, and home-to-work commuting in particular, is the spatial structure of a territory. The spatial distribution of housing and employment plays an important role in determining transport modes and distances travelled, and consequent geographical variations in overall commute-energy consumption.

Although the commute in Western countries represents a decreasing share of overall traffic (Pisarski, 2006, p. 2), this form of mobility continues to be a rewarding research topic because of the availability of extensive survey data. In Belgium, which is the subject of our study, long-distance commuting has been organized and promoted by the state since the middle of the nineteenth century. The cornerstones of this policy, which remains in place today, consist of the construction of an extensive railway network and subsidized commuter rail subscriptions. It is fair to say that the commute in Belgium has been institutionalized as a means of achieving national industrialization and moderate urbanization. During the industrial revolution, a highly decentralized spatial structure developed mainly around railway stations, but in Belgium today, as in the rest of Europe, the commute is largely done by automobile (Grosjean, 2010).

From the 1980s, Belgium has evolved into a federal state consisting, geographically speaking, of three regions: Flanders (in the north, Dutch speaking), Wallonia (in the south, French speaking) and Brussels (the centrally located capital region, which is officially bilingual). These three regions are distinguished by important socio-economic and geographical differences. The economy of Flanders, which includes 
about 6 million inhabitants, is strongly oriented toward logistics (port industries), service industries and research and development activities, which make it a strong player in a globalizing economy. The Walloon economy (with about 3.5 million inhabitants), however, is still undergoing transition from a historical industrial base, and therefore experiences difficulties maintaining adequate employment. The Brussels capital region, on the other hand, has a rather prosperous economy based mainly on the presence of international institutions and company headquarters and considerable concentrations of financial, technological, and consultancy businesses. Since Brussels is a densely populated city region with just over 1 million inhabitants, many rather specialized jobs in the capital region are taken by well-paid employees who live not in Brussels, but in Flanders or Wallonia. The consequences of this situation include a combination of disproportionate unemployment rates in the Brussels capital region and a rather excessive, state-facilitated, Brussels-bound commute. A final but interesting geographical element that distinguishes Flanders in particular from Wallonia is the topography. Although both regions may be characterized as historically polycentric in terms of urban structure, Flanders is almost flat whereas Wallonia has a rather pronounced undulating topography. In terms of transport, this means that cycling is common in the north, but is almost non-existent in the south. In addition, both heavy and light rail networks are more abundant and usually also faster in Flanders compared with Wallonia, implying that public transport is probably more attractive and often more efficient in the northern region.

Hubert and Toint (2002) report that $18 \%$ of all trips in Belgium terminate at the workplace or at school ${ }^{1}$. In Flanders, the Travel Behaviour Survey - OVG 2001 (Zwerts and Nuyts, 2004; Witlox, 2007) points out in more detail that the home-to-work commute represents $21 \%$ of all trips, or $35 \%$ of all daily travelled kilometres. In 
Wallonia, the home-to-work commute represents $38 \%$ of kilometres travelled in a working day, which accounts for $22.6 \%$ of all trips (IWEPS, 2008). Since commonly known adverse effects of transport, such as emissions, accidents and economic dependence on imported fuel are highly correlated with physical distance travelled (Van Acker et al., 2011), we may conclude that roughly one-third of these effects of daily person mobility in Belgium are caused by commuter traffic.

\section{Study objective}

We argue that the combination of a common history and a uniform commuting policy and notable differences in spatial structure and economic development, provides an interesting basis for investigating differences between the three mentioned regions in terms of the sustainability of the commute.

Until 2001, the Belgian commute was particularly well documented through the decennial census, which provided trip length and used main travel mode for most of the active population, along with the residential address of respondents.

Since sustainability is a very broad concept, and therefore difficult to measure, we have chosen the commute-energy performance (CEP) index as a proxy. Based on a straightforward combination of distance travelled and mode choice, CEP was introduced by Boussauw and Witlox (2009). The index is calculated by geographical zone, which is considered as the residential location of the theoretical "average commuter". The idea of using energy consumption as a sustainability indicator was first proposed by Newman and Kenworthy (1989), who demonstrated a link between the residential density of a series of cities, and gasoline consumption per capita. Although the methodology used by Newman and Kenworthy (1989) has been heavily criticized for its demarcation of the assessed cities (Mindali et al., 2004), the concept of 
measuring the sustainability of travel through energy consumption rates remains valid. Nevertheless, we have extended their method by studying spatial variations in this variable throughout an urban region with varying spatial and economic characteristics, instead of limiting the observations to inside an arbitrarily demarcated city border. We wish to explore possible links between changes in CEP in the regions between 1991 and 2001, and regional characteristics such as regional economic development, the proximity of housing stock to the labour market, residential compactness, the supply of public transport and the suitability of the topography for commuting by bicycle. In addition, the available census data allow us to explore links with demographic change and assess if population dynamics are compatible with reaching governmental travel energy reduction targets.

\section{Method}

Our evaluation of transport energy consumption is based on Boussauw and Witlox's (2009) CEP index, which for each census block takes into account average home-towork distances by travel mode, and average energy consumption rates by travel mode. In Belgium, a census block represents the most detailed level of commuter data aggregation. Census block data allow for detailed studies of gradients and consideration of functional regions (consisting of urban cores surrounded by catchment areas) as opposed to isolated cities.

The index is obtained by dividing the total amount of energy consumption for home-to-work travel registered in a census block by the working population (active workforce) living in that census block. More formally:

$$
C E P_{s}=\frac{D_{s} \cdot \sum_{i} \bar{E}_{i} \cdot c_{i, s}}{N_{s}}
$$


Here:

$C E P_{s}=$ energy performance per member of the active workforce for home-to-work travel from the considered (statistical) census block $s$;

$D_{s}=$ total distance travelled (one way) for home-to-work travel from the considered census block $s$;

$\bar{E}_{i}=$ mean energy consumption per passenger for the considered mode $i$;

$c_{i, s}=$ correction factor for the considered mode $i$, within the census block $s$

$N_{s}=$ number of members of the active workforce in the considered census block $s$.

The applied correction factor adjusts for the loss of accuracy resulting from the use of geographically aggregated data and introduces the average distance per trip by travel mode. Accuracy is limited since the disaggregated data from the 1991 census are not available for privacy reasons. Energy consumption rates by travel mode were calculated for the Belgian context and are presented in Table 1.

\begin{tabular}{lccc}
\hline Mode & Flanders $^{1}$ & Wallonia $^{\mathbf{2}}$ & Brussels $^{\mathbf{3}}$ \\
\hline Car & 0.45 & 0.45 & 0.45 \\
Motorcycle & 0.41 & 0.41 & 0.41 \\
Metro, Tram, Bus & 0.26 & 0.35 & 0.12 \\
Train & 0.15 & 0.15 & 0.15 \\
Bicycle & 0.00 & 0.00 & 0.00 \\
On foot & 0.00 & 0.00 & 0.00 \\
${ }^{1}$ Based on (Teller et al. 2010) & & \\
${ }^{2}$ Teller et al. (2010) & & \\
${ }^{3}$ Based on Teller et al. (2010) and MOBEL 1998-1999 (Toint et al. 2001) \\
\hline
\end{tabular}

Table 1 . Average energy consumption by mode in Belgium (kWh/pkm)

Figures for the Walloon region were obtained by dividing the total amount of energy consumed for a given travel mode, calculated on the basis of the annual 
kilometres travelled and the fuel type, by the occupancy rate of the mode. Details of the calculation have been published in Teller et al. (2010), while the Walloon Air and Climate Agency (AWAC) provided the underlying data.

Results are expressed in kWh per passenger-kilometre. In order to standardize calculations for the three regions, the Walloon figures for automobile, motorcycle and train modes of travel have been applied to the Flanders and Brussels regions, whereas figures for the metro, bus and tram have been adapted to the regional context of the two latter regions. This arrangement stems from considerable differences in fleet composition and passenger ratios. In Brussels, most kilometres travelled by public transport are covered by the metro and tramway networks, with high patronage and superior energy efficiency rates. Travel by light rail is statistically absent from the local and regional transport options for Wallonia, resulting in a less-attractive diesel-based bus network. In Flanders, light rail is somewhat more available, representing about 7\% of all regional and local public transport services.

A limitation to using the obtained energy consumption rates is that they are regional averages. Yet, occupation rates of public transport may vary significantly depending on the nature (urban or rural) of the area and on the time of the day or the week. Moreover, in the case of motorized travel modes, congestion is not taken into account, although more energy per kilometre is consumed when driving in congested traffic. A similar caution may be expressed regarding travel speed: in some regions, the availability of non-congested motorways may allow above-average speeds, which may again lead to excessive energy consumption rates.

Travel data used for the calculation of the CEP index in 2001 and its change between 1991 and 2001 were extracted from the 1991 and the 2001 censuses (National Socio-Economic Surveys, or SES). The 2001 SES is the last-conducted ${ }^{2}$ decennial 
comprehensive census survey of the entire Belgian population over six years old (Thomas et al., 2008). The general response rate was about $95 \%$ with some variations in sections of the questionnaire (Verhetsel et al., 2007).

Our analysis only took into account people travelling daily to a fixed working place (home-to-work commuters). Workers with variable work places or those who worked from home were not asked to complete the questions regarding mobility in the SES.

A comparison of CEP rates for 1991 and 2001 requires taking into account some accuracy issues, since the two datasets apply different levels of data aggregation. Data from 1991 are aggregated by census ward, while data from 2001 are available at the individual level. Similarly, distance travelled is aggregated by distance class for 1991, while individual figures are available for 2001. To address these issues, we adopted a less detailed data level for calculating the CEP index change between 1991 and 2001, with the result that the 2001 CEP index was recalculated using distance classes. Although we reduced data accuracy using this approach, we obtained a more accurate comparison of average trip lengths over time.

In addition to travel data, we used population data to monitor demographic changes in Belgium between 2001 and 2010 obtained from the Federal Public Services (FPS) Economy, Directorate-General Statistics and Economic Information (DGSEI) population surveys.

We explored regional differences by mapping our CEP values against existing knowledge of specific regional characteristics, with a focus primarily on areas with significantly higher or lower average scores. We applied a regression model to gauge links with job market proximity and residential compactness. We then assessed change in CEP between 1991 and 2001. Land use, spatial structure and socio-economic factors 
were taken into account to explore observed cross-regional and temporal variations. Finally, regional variations in population dynamics between 2001 and 2010 were assessed for their potential for a more sustainable commuting structure. Although this sustainability potential estimate is based on somewhat outdated data, we argue that the spatial-economic structure has changed little since 2001. Consequently, an assessment based on population figures for 2010 is useful in developing general insights into the development of the commuting structure.

\section{Exploring regional differences in commute-energy}

\section{performance in Belgium}

\section{Exploring 2001 CEP values}

The CEP index was calculated for all census wards in Belgium for the reference year 2001, and is illustrated in Figure 1 and Table 2. For an average borough ${ }^{3}$, less energy is consumed in home-to-work commuting in Flanders $\left(8.2 \mathrm{kWh} /\right.$ pers.-trip $\left.{ }^{4}\right)$ than in Wallonia (11.0 kWh/pers.-trip). Commuters living in Brussels are much more energy efficient again ( $4.1 \mathrm{kWh} /$ pers.-trip). An observed greater variability in travel behaviour in the southern region of the country is highlighted by the higher standard deviation value of Wallonia compared with Flanders (2.4 and $1.6 \mathrm{kWh} /$ pers.-trip, respectively). The wider spread of values in Wallonia is perhaps related to the higher variation in spatial characteristics, such as population density, urbanization and economic development compared with Flanders. A comparison of the 10th percentile for Wallonia (8.0 kWh/pers.-trip) with the average CEP index for Flanders ( $8.2 \mathrm{kWh} /$ pers.-trip) emphasizes that only $10 \%$ of Walloon boroughs are below the Flemish average 
consumption rate. Note that the figures below are based on the aggregated values by borough; they are not statistics based on individual commuters.

\begin{tabular}{|c|c|c|c|c|c|c|c|c|}
\hline \multirow[b]{2}{*}{ Mode } & \multicolumn{3}{|c|}{1991} & \multicolumn{3}{|c|}{2001} & \multicolumn{2}{|c|}{ 1991-2001 evolution } \\
\hline & Flanders & Wallonia & Brussels & Flanders & Wallonia & Bruss els & Flanders & Wallonia \\
\hline $\mathrm{N}$ & 1119 & 1471 & 27 & 1119 & 1471 & 27 & & \\
\hline Missing data & 1 & 3 & 0 & 0 & 1 & 0 & & \\
\hline Mean & 7.6 & 9.5 & 4.0 & 8.2 & 11.0 & 4.1 & 8.2 & 16.1 \\
\hline Median & 7.5 & 9.3 & 3.8 & 8.1 & 10.8 & 4.2 & & \\
\hline $\begin{array}{l}\text { Standard } \\
\text { deviation }\end{array}$ & 1.7 & 2.3 & 0.6 & 1.6 & 2.4 & 0.5 & & \\
\hline $10 \%$ percentile & 5.5 & 6.5 & 3.2 & 6.2 & 8.0 & 3.2 & 17.8 & 23.5 \\
\hline $25 \%$ percentile & 6.5 & 7.8 & 3.5 & 7.1 & 9.3 & 3.8 & 9.5 & 19.3 \\
\hline $75 \%$ percentile & 8.6 & 10.9 & 4.4 & 9.1 & 12.3 & 4.5 & 6.9 & 13.6 \\
\hline $95 \%$ percentile & 10.2 & 13.7 & 4.9 & 10.9 & 15.5 & 4.8 & 6.7 & 12.6 \\
\hline
\end{tabular}

Table 2. Statistical features of the CEP index distribution by region, by borough (kWh/pers.-trip)

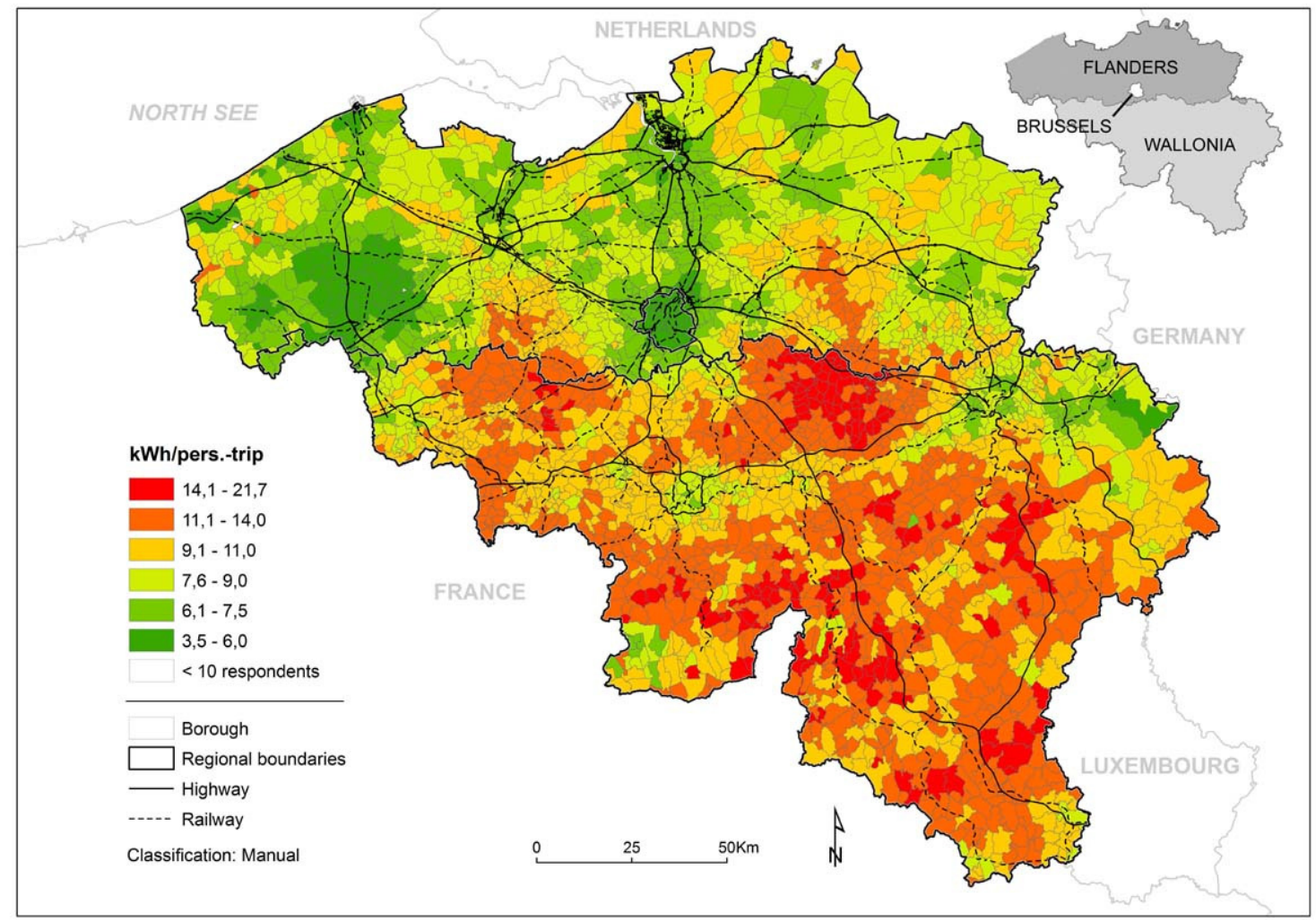


Figure 1: Energy efficiency of home-to-work commuting in Belgium in 2001 (borough)

In Wallonia, boroughs showing high CEP (i.e. low CEP values) are found in densely populated areas. The two main urban agglomerations, Liège and Charleroi, and the main cities of Mouscron, Tournai, Mons, Namur, Verviers, and Eupen are among the most energy efficient areas of Wallonia. Many localities outside the old industrial basin also represent low consumption rates. The majority of these are small towns on the south-south-east periphery of Brussels, while others are located in the southern, less densely populated part of Wallonia. All of these areas concentrate on employment and population, offering a high degree of mixed land use and sufficient employment at the local level. These two characteristics infer shorter commuting distances, greater potential patronage of the public transport system and more energy efficient commuting patterns.

Boroughs with high energy consumption rates are usually located far from employment centres, which infers long commuting distances. Further, support for public transport is below average in these areas, making the automobile the paramount mode of travel. Both aspects contribute to higher energy consumption rates and higher GHG emission levels. At the regional level, the described phenomenon can be observed mainly in areas that are located $30 \mathrm{~km}$ or more from the main cities of Wallonia and from the metropolitan areas of Brussels and Luxembourg. A general observation is that the further commuters are located from centres of population and employment concentrations, the higher their observed energy consumption.

In Flanders, high scores are observed in the metropolitan areas around (and including) Antwerp and Brussels, incorporating the corridor between these cities which contains the city of Mechelen, and extending towards the city of Leuven. Other areas that score well are the region of Kortrijk-Roeselare-Leie, the surroundings of Ghent 
(especially the northern part which is close to the port industry), and some regional cities (Hasselt-Genk, Brugge). In the very western part of Flanders, low CEP values are of minor importance because of the small number of residents in this rural area.

Areas showing rather low scores are the south of the province of OostVlaanderen (where employment is low), the south (around the E40 motorway) and west of the province of Limburg and the adjacent (eastern) part of the province of VlaamsBrabant. The urban sprawl of the western part of the E40 motorway also appears to have induced some long-distance commuting.

The high scores for the Brussels capital region indicate it is performing rather impressively in comparison with the other two regions. However, the comparison is not straightforward since the Brussels capital region consists of a very compact urban area. Commuters who live in Brussels do not only travel to work over much shorter distances than the rest of the population of Belgium, they are also more frequent users of local public transport. Moreover, its high public transport patronage rates and high density of electric rail urban transit contribute to a lower amount of energy consumption per passenger-kilometre in public transport in Brussels compared with the rest of Belgium. However, it is possible that results could be biased somewhat by the relatively lower efficiency of automobile trips due to disruptions and delays in traffic flows in the Brussels area compared with outside this area. Nevertheless, because the labour supply for the Brussels economy lives outside Brussels, both Brussels and the surrounding commuter municipalities are highly dependent on the long-established mass commute.

\section{Explaining 2001 CEP values}

These qualitative findings are supported by a multivariate regression analysis that aims to explain CEP in terms of job market proximity, residential compactness, and inherent 
regional differences (Antipova et al., 2011). The following independent variables were included.

- Modal share: The share of commuters living in the considered borough who do not commute by automobile (source: SES 2001).

- Population density: Obtained from the 2001 SES. Because of the observed deviation from the normal distribution, this variable was subjected to a logarithmic transformation.

- Compactness of municipality: The proportion of the population not living in an area defined as a residential core. Residential cores are defined and demarcated by DGSEI. This DGSEI demarcation is generally accepted in Belgian geographical research.

- Job accessibility: The number of jobs within a $20 \mathrm{~km}$ radius of the place of residence. This threshold is based upon the average commuting trip length of $20 \mathrm{~km}$ in Belgium. Because of the observed deviation from the normal distribution, this variable was subjected to a logarithmic transformation.

- A dummy variable for the Flemish region (using the Brussels region as a reference).

- A dummy variable for the Walloon region (using the Brussels region as a reference). An exploratory ordinary least squares analysis showed a significant effect on CEP for all independent variables. However, because of the spatial aggregation of the observed variables, spatial autocorrelation (based on a significant Moran's I value) was observed, meaning that the obtained significance levels were unreliable.

In a second phase, a "spatial error" regression was applied with controls for the correlation of the error terms of neighbouring areas by means of the spatial-analytical 
GeoDa software (Anselin et al., 2006). The obtained spatial regression results show that "compactness of municipality" no longer had a significant influence. This is in line with previous research (Boussauw, 2011, p. 231) showing that compactness of cores mainly affects non-commuting trip lengths. Although this finding gives us some material for a more thorough discussion on the definition of compactness, we believe such a discussion is beyond the scope of this paper. Consequently, we have excluded the "compactness" variable from the analysis.

\begin{tabular}{lrr} 
pseudo- $R^{2}=0.80$ & $r$ & $p$-value \\
\hline (constant) & 10.12 & 0.00 \\
share of car use & 0.09 & 0.00 \\
ln of population density & -0.16 & 0.00 \\
ln of job accessibility & -0.68 & 0.00 \\
Flanders (dummy) & 0.24 & 0.62 \\
Wallonia (dummy) & 1.44 & 0.00 \\
\hline
\end{tabular}

Table 3. Spatial "error" regression results

The dummy variable for Flanders was not significant, whereas the dummy for Wallonia was significant (Table 3). This result indicates a difference between the structure of CEP in Wallonia and the structure of CEP in Flanders and Brussels, which was not captured by the independent variables employed. The non-significant difference between Flanders and Brussels is possibly explained by the geographical location of the Brussels labour market near to the potential labour supply in Flanders. Geographically speaking, Wallonia is further away from the Brussels labour market, while the Walloon labour market itself presents less job availability compared with the rest of the country. 
Generally, boroughs located close to main cities are characterized by a low CEP index, while those located further from city centres present much higher consumption rates. Such concentric structures can be referred to as the Alonso-Muth model (see Verhetsel et al., 2007), as transport cost increases with increasing distance from the central business district. However, the observed north-south distinction is more remarkable. The south of the country is characterized by longer trip lengths, mainly because of a weak job market. This leads to lower CEP rates, a symptom that is reinforced further by a weaker public transport system, an undulating topography and high average driving speeds.

Commuting trip lengths are shorter in the northern part of the country because of the higher population density, a stronger job market, and a higher degree of functional mix. Combined with a more attractive public transport system and a higher share of non-motorized users, this explains a large part of the quite low CEP in Flanders. However, as expected, inhabitants in Brussels rather impressively exceed the standards set by the other two regions. The number of jobs available within a radius of $20 \mathrm{~km}$ provides a quantitative basis for the observed differences between the three studied regions. In Wallonia, an average of 90,000 jobs is found within the applied radius around a typical borough. In Flanders, however, this number rises to 270,000, while in Brussels no less than 900,000 jobs are available within this radius. The 1 to 3 ratio between a typical borough in Wallonia and Flanders partly explains observed differences in CEP values between the two regions. However, we should stress that the mentioned mean values qualify accessibility to employment from a spatial rather than an individual household perspective (Kwan and Weber, 2008). Boroughs located at a distance from job centres are less densely populated, although this is progressively changing, as will be discussed below. 
Another aspect to be taken into account is that the map (Figure 1) only shows the CEP of commuters who live in Brussels. Commuters who work in Brussels will show rather high CEP values, because of the higher concentration of jobs (Boussauw et al., 2011), entailing long-distance travel. This means the compact urban structure of Brussels may have contradictory effects on overall CEP.

\section{Development of the CEP index in Belgium between 1991 and}

\section{1}

In Belgium, the CEP index rose from $6.7 \mathrm{kWh} /$ pers. in 1991 to $7.6 \mathrm{kWh} /$ pers. in 2001

(see Table 4). This stronger development of the CEP index (+13.8\%) against the development of the average trip length $(+9.3 \%)$ can be explained by the overall decrease of non-motorized travel mode shares during the same period. Wallonia demonstrated the strongest CEP index increase $(+19.5 \%)$, while the increase in Brussels was only $+2.5 \%$. Flemish commuters consumed more energy than did commuters residing in Wallonia. However, the share of the national commute-energy consumption decreased from $61.0 \%$ to $59.3 \%$ between 1991 and $2001(-2.8 \%)$. This trend can be compared with the development of the regional share of the national job supply. In the north, the share of the total number of jobs increased by $+1.5 \%$, while in the south it decreased by $-8.6 \%$. These figures were calculated based on disaggregated values. 


\begin{tabular}{|c|c|c|c|c|c|c|c|c|c|c|c|c|}
\hline & \multicolumn{4}{|c|}{1991} & \multicolumn{4}{|c|}{2001} & \multicolumn{4}{|c|}{ 1991-2001 Evolution } \\
\hline & $\mathrm{F}$ & W & $\mathrm{Bxl}$ & $\mathrm{B}$ & $\mathrm{F}$ & W & $\mathrm{Bxl}$ & $\mathrm{B}$ & $\mathrm{F}$ & W & Bxl & $\mathrm{B}$ \\
\hline Average trip length $(\mathrm{km})$ & 17.6 & 20.1 & 11.2 & 17.8 & 18.7 & 23.3 & 11.4 & 19.5 & 5.8 & 16.0 & 1.5 & 9.3 \\
\hline Average CEP index (kWh/pers.trip) & 6.7 & 7.8 & 4.0 & 6.7 & 7.4 & 9.3 & 4.1 & 7.6 & 10.1 & 19.5 & 2.3 & 13.8 \\
\hline Total energy (GWh) & 11.1 & 6.2 & 0.9 & 18.2 & 15.1 & 9.3 & 1.1 & 25.4 & 35.2 & 48.9 & 19.3 & 39.1 \\
\hline Share of total energy $\%$ & 61.0 & 34.1 & 4.8 & 100 & 59.3 & 36.5 & 4.2 & 100 & -2.8 & 7.0 & -14.2 & - \\
\hline Share of jobs $(\%)$ & 57.2 & 26.9 & 15.9 & 100 & 59.8 & 24.6 & 15.0 & 100 & 4.5 & -8.6 & -5.7 & - \\
\hline Population (Millions) & 5.8 & 3.3 & 1.0 & 10.0 & 6.0 & 3.4 & 1.0 & 10.3 & 3.5 & 3.0 & 2.0 & 3.2 \\
\hline
\end{tabular}

Table 4. Statistical features of the CEP index distribution by region $(\mathrm{F}=$ Flanders, $\mathrm{W}=$ Wallonia, $\mathrm{Bxl}=$ Brussels, $\mathrm{B}=$ Belgium)

Figure 2 highlights the development of the CEP index between 1991 and 2001, based on the average CEP value by borough. Energy consumption growth was faster in Wallonia, especially in the southern part of the region. The CEP index increased by less than $+10 \%$ across most of Flanders. Again, this can be partly explained by the stronger job market in Flanders vis-a-vis Wallonia (Marissal et al., 2006). When more job opportunities are available locally, workers are not forced to travel long distances to find a job. The 1991-2001 CEP index development also maps areas where the CEP values decreased. These can be observed mainly from 15 to $35 \mathrm{~km}$ around the southern periphery of Brussels. Other areas with decreasing percentages are often sparsely populated, making their CEP value less significant. 


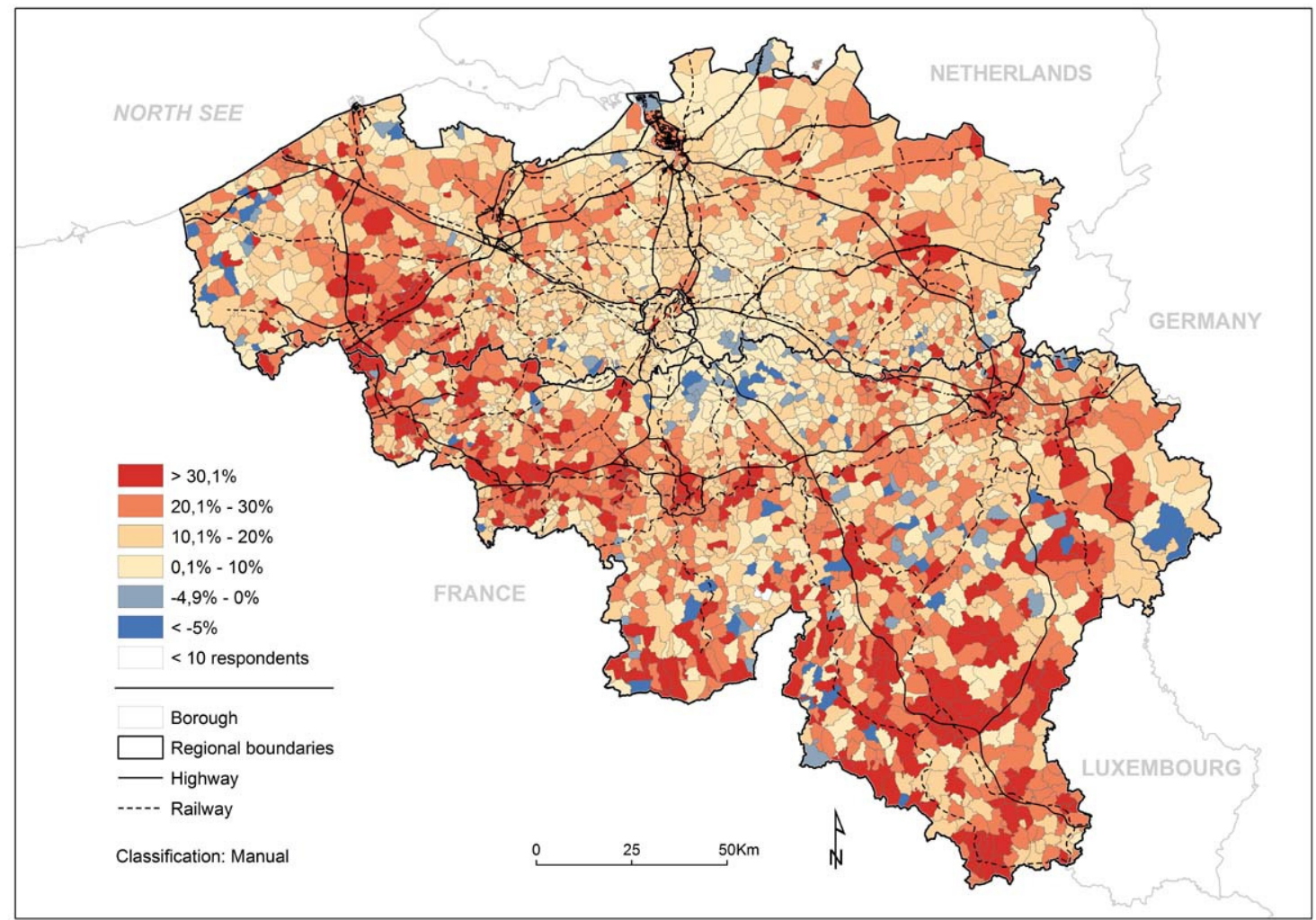

Figure 2. Development of the CEP index for Belgium between 1991 and 2001 (borough)

A comparison of land use, spatial structure and socio-economic factors underlines cross-regional variations, but also sheds light on features common to Flanders and Wallonia.

In Wallonia, the strong increase of the CEP index observed in the southern part of this region (over $+30 \%$ ) can be explained by the decrease in local job opportunities between 1991 and 2001 (partly because of a decline in the agriculture sector) and the increasing dependence of rural and small-town dwellers on the automobile. In addition, over the considered period, this area witnessed the arrival of new residents working in the main employment centres of Wallonia and Luxembourg. The strong attractiveness of Luxembourg, and the country's scarcity of available land, means that Belgian households working in Luxembourg live further and further from the border. Within 
those areas construction land is more available and housing is more affordable (Carpentier, 2010).

In Flanders, a modal shift towards the automobile and an increase in the distance travelled to work has led to a strong increase of the CEP index in the area of KortrijkRoeselare-Leie and in the eastern province of Limburg. As a partial explanation of the development of energy efficiency in these areas, although the use of the bicycle in 2001 remained above $12 \%$ in some of these areas, it fell critically between 1991 and 2001, to the advantage of the automobile (Verhetsel et al., 2007).

The major and smaller cities and their peripheries in Flanders and Wallonia regions share similar features. As shown on the map (Figure 1), most urban centres showed an increase of the CEP index between 1991 and 2001, while outside Brussels (including the north of Wallonia) and outside most cities in Flanders, commute-energy efficiency was relatively improved. This trend is confirmed in Table 2: the 1991-2001 development of the four percentile values of the CEP index in Wallonia and Flanders reveals that commute-energy consumption increased mainly in the most energy efficient areas of the country (generally the urban centres). In contrast, peripheral areas tend to represent slower CEP rate growth values in both Wallonia and Flanders.

On the one hand, the decrease of commute-energy efficiency in cities can be explained by the economic shift toward service industries. From a geographical point of view, this transformation relies mainly on agglomeration effects that are mainly present in the capital region, but to a certain extent also in Antwerp. This becomes particularly clear in cities of the old Walloon industrial basin where the number of workers commuting to Brussels, Lille (France) or Luxembourg increased significantly between 1991 and 2001. On the other hand, high consumption rates in cities are also due to the decentralization of businesses outside main urban agglomerations. The migration of 
many activities (including industrial zones, retail centres, hospitals, and business parks) from traditional urban locations to cheaper peripheral locations, combined with monofunctional development and limited access to public transport, has led to an increase of the average distance travelled by urban residents, and thus to higher energy consumption. In addition, the growing importance of agglomerations in terms of number of jobs has also enlarged the opportunity range of urban residents, which may have led to longer distances travelled, and thus to a larger amount of energy consumed in the commute.

In peripheral areas, decentralization has brought jobs closer to workers, and thus lowered average journey lengths and energy consumption. This has mainly affected areas around Brussels, including municipalities across the French-Dutch language border. A decrease in the required amount of energy for the commute is also observed around the main urban centres of Flanders, but is not discernible in the surroundings of

the main cities of Wallonia. The relatively high population density and the important job creation rates in these areas have bridged the mismatch between employment opportunities and accommodation observed in other peripheral locations of the country. Nonetheless, as most of the population lives in urban areas, the locally observed decrease in commute-energy consumption only affects a small part of the working population, so an overall increase of distance travelled and energy consumed is still observed at the national level.

\section{Recent demographic changes in terms of commute dependency}

Demographic changes in Belgium between 2001 and 2010 highlight the current challenges in terms of CEP, taking into account the observed trend in commuting over the 1991-2001 period. Indeed, considering the spatial patterns of demographic trends 
may help in understanding the way commuting efficiency may develop over time: to what extent is the population growing more slowly in areas that perform well in terms of commute-energy consumption? Alternatively, are energy inefficient areas characterized by strong population gains?

As presented in Figure 3, most areas of Belgium are characterized by a population increase between 2001 and 2010. In Wallonia, the strongest growth was observed outside the main cities, especially in the south-eastern periphery of Brussels and near the Luxembourg border. In Flanders, the most important population gains were found in the main cities (Ghent, Antwerp, Leuven and part of the agglomeration around Brussels), but also near the coast and near the border with The Netherlands. Brussels showed a particularly strong population increase in the western part of the agglomeration.

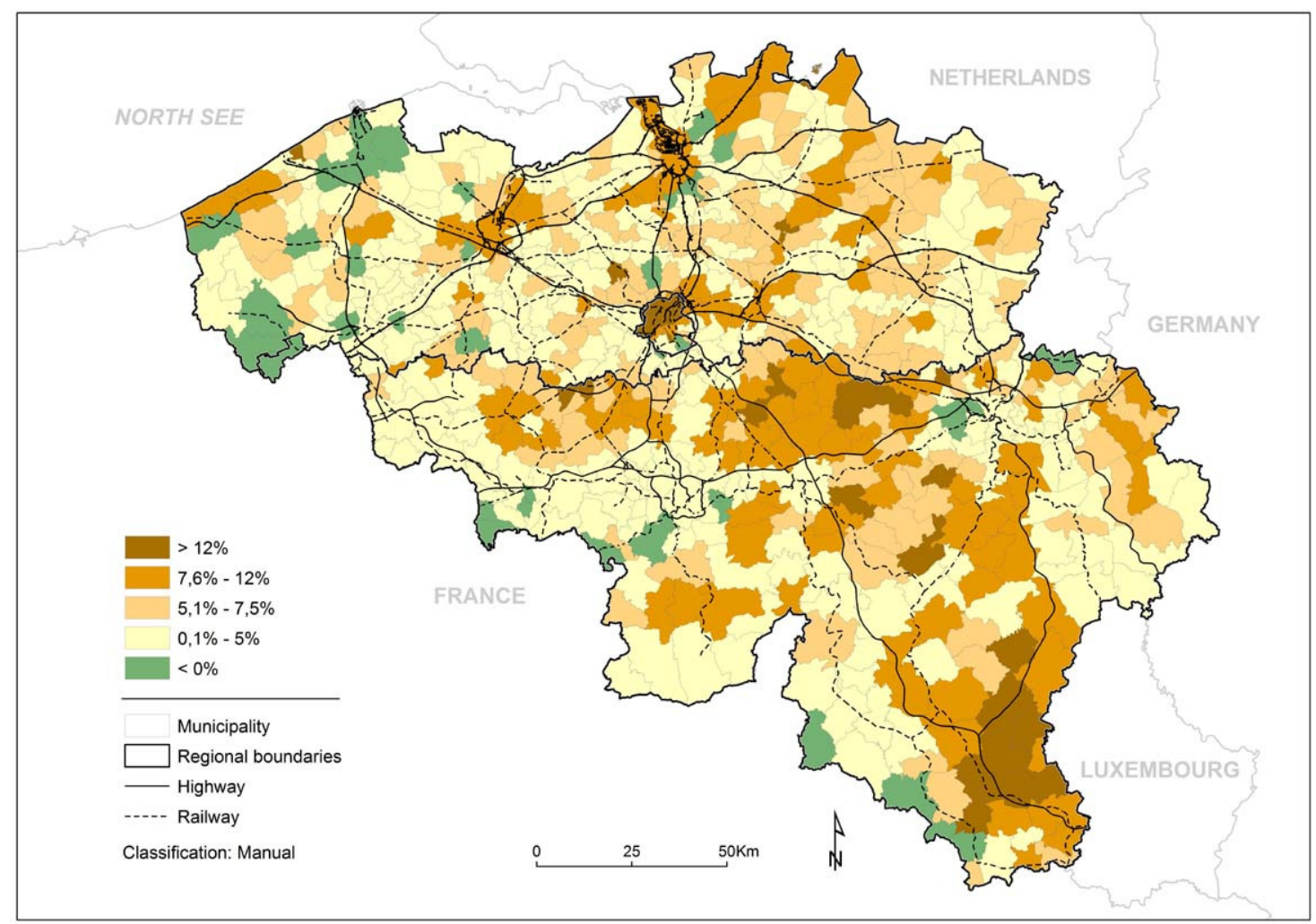

Figure 3. Population changes in Belgium between 2001 and 2010 (by municipality) 
Such spatially differentiated patterns of population change between Wallonia and Flanders but also across regions have contrasting impacts on CEP. To illustrate this fact, Figure 4 reveals strong contrasts between population changes over the period 2001-2010 and the deviation of the 2001 CEP index from the national average.

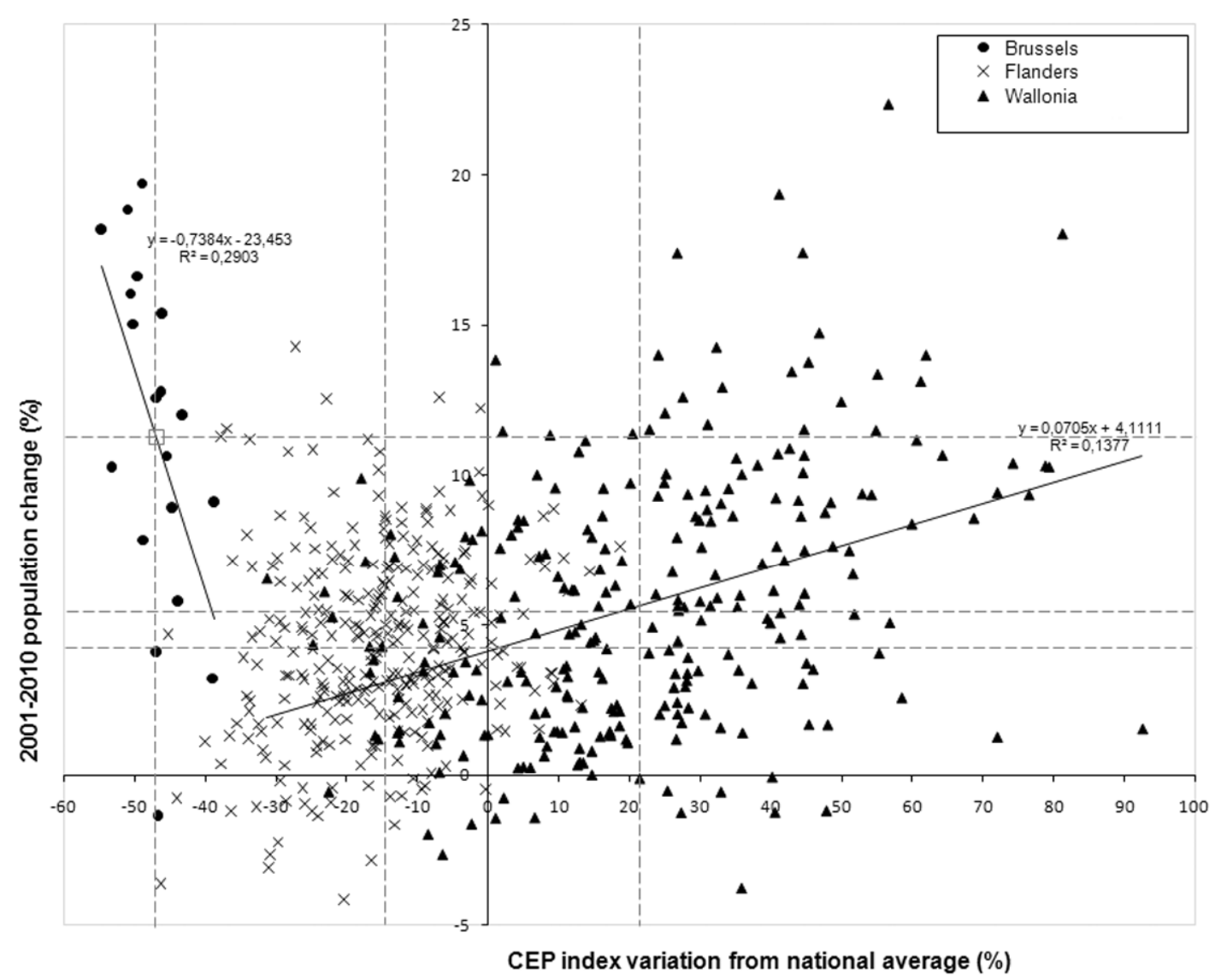

1 Note that regression equations are only presented to illustrate the major differences in trends between regions. No equation is presented for Flanders as no clear tendency could be observed and the $\mathrm{R}^{2}$-value was extremely low. Since the regression is applied on zones that share borders (and not on individual respondents) spatial autocorrelation may occur, causing some bias of the coefficients and $\mathrm{R}^{2}$-values.

Figure 4. Comparison of the 2001 CEP index deviation from the national average and 2001-2010 population changes by region, by municipality

A comparison between Brussels, Flanders and Wallonia sheds light on substantial regional differences. In Wallonia, municipalities are, on average, characterized by a CEP index above the national average, and only a few are under the 
Flanders average. Inside Flanders, the CEP of most municipalities is under the national average, but most importantly, none of them is above the Walloon average.

In Wallonia, CEP index deviations from the national average tend to be stronger in areas where population growth is important: areas where home-to-work commuting was more energy consuming in 2001 are now those generally showing the highest increase in population between 2001 and 2010. This development is not accidental, but originated in the migration flows of Walloon families who are increasingly dependent on the Brussels labour market. For many of them, moving to the Brussels capital region is not a real option, given soaring real estate prices or lifestyle preferences that may be incompatible with a metropolitan residential environment. In addition, migration to the Flemish suburban municipalities around Brussels is only a second option for many French-speaking Belgians, because of language issues and implicit politics that are restricting the construction of new dwellings in these municipalities. Thus, we may view the growth of the peri-urban commuter municipalities in the north of Wallonia as a spillover effect of the growth of the Brussels job market. In the south of Wallonia, we observe a similar trend focused on the Luxembourg economy.

Correlations are less obvious in Flanders: although it also shows a slightly positive trend, its scattered distribution pattern confirms that between 2001 and 2010 energy efficient areas witnessed either population gains or population losses.

On the other hand, the evidence in the case of Brussels is a particularly strong observed negative correlation among the 19 municipalities. This means that the strongest population growth between 2001 and 2010 occurred in the most energy efficient areas. 


\section{Conclusions and perspectives}

This paper addresses the commute sustainability issue in Belgium. A comparison of Flanders and Wallonia puts the issue in the perspective of trends perceived in the Brussels capital region. Comparing these two regions is of real interest given their combinations of common inherited features such as a dense settlement pattern of smalland medium-sized cities and villages with marked differences in economic base. It appears that, on average, proximity to the job market is much higher in Flanders and Brussels compared with Wallonia. On average, less energy is consumed for home-towork commuting in Flanders compared with Wallonia. Apart from differences in land use, spatial structure and topography, socio-economic factors explain spatial and temporal variations inside and between regions. In both regions, boroughs with a high CEP index are found in densely populated areas, although the contribution of residential compactness depends on the regional context. Boroughs with high energy consumption rates are usually located at distances from employment centres, record excessive commuting trip lengths, and have poor access to public transport. Therefore, longdistance automobile travel represents the most common form of commuting, generating substantial GHG emissions. This observation is salient to areas located $30 \mathrm{~km}$ and more from main urban agglomerations.

Between 1991 and 2001, most urban centres in Belgium showed an increasing CEP index, while commute-energy efficiency improved in the immediate surroundings of Brussels (including the north of Wallonia) and areas adjacent to most cities in Flanders. The decrease of commute-energy efficiency in cities can be explained by a "metropolization" effect and the decentralization of businesses outside the main urban agglomerations. In peripheral areas, decentralization has led to shorter average journeys and thus less energy consumption. However, we observe an overall increase of distances 
travelled and energy consumed at the national level, as areas where CEP values have decreased are often sparsely populated.

Since the geographical distribution of the population appears to play an important role in commute-energy efficiency, we surveyed population changes in Belgium between 2001 and 2010. In Wallonia, areas where the commute was more energy consuming in 2001 are those which generally represent the fastest population growth between 2001 and 2010. In contrast, growth distribution of the Flanders population is rather neutral in terms of CEP. Therefore, important population growth in municipalities that already perform under average in terms of commute-energy is bound to have a negative impact on average household commute-energy consumption in the future.

Nonetheless, the point that spatial development and sustainability of transport are not necessarily linked through demographic trends and characteristics is a salient one. The price instability of fuel (e.g. in the light of peak oil) may have major impacts on residential and business location choices. These in turn may lead to new forms of travel pattern differentiation and an improved jobs-housing balance.

\section{Acknowledgements}

The University of Liège's contribution to this paper is based on a two-year research project led by the Standing Conference on Territorial Development (http://cpdt.wallonie.be/), which is financed by the Walloon Region. The Ghent University's contribution was funded by the Policy Research Centre on Regional Planning and Housing - Flanders (Steunpunt Ruimte en Wonen 2007-2011). We are grateful to the FPS Economy - Directorate-General Statistics and Economic Information for providing data.

\section{Notes}


1. Home-to-school travel is not included in the analysis discussed in this paper.

2. It should be emphasized that the kind of research presented in this paper could not have been carried out based on a survey sample. It is therefore highly regrettable that the decennial Belgian socio-economic survey was abandoned and therefore not repeated in 2011.

3. We adopt the term "borough" here to refer to a "former municipality", i.e. a municipality in the former Belgian administrative system (before 1977).

4. Meaning: a one-way trip.

\section{References:}

Aleklett, K., M. Höök, K. Jakobsson, M. Lardelli, S. Snowden, and B. Söderbergh. 2010. The peak of the oil age: Analyzing the world oil production reference scenario in World Energy Outlook 2008. Energy Policy 38 (3):1398-1414.

Anselin L., I. Syabri, and Y. Kho. 2006. GeoDa: An introduction to spatial data analysis. Geographical Analysis 38 (1): 5-22.

Antipova, A., F. Wang, and C. Wilmot. 2011. Urban land uses, socio-demographic attributes and commuting: A multilevel modeling approach. Applied Geography 31 (3): 1010-1018.Banister, D. 2005. Unsustainable transport: city transport in the new century. New York: Routledge.

Blanco, H., M. Alberti, R. Olshansky, S. Chang, S. M. Wheeler, J. Randolph, J. B. London, J. B. Hollander, K. M. Pallagst, T. Schwarz, F. J. Popper, S. Parnell, E. Pieterse, and V. Watson. 2009. Shaken, shrinking, hot, impoverished and informal: Emerging research agendas in planning. Progress in Planning 72 (4):195-250.

Boussauw, K. 2011. Aspects of spatial proximity and sustainable travel behaviour in Flanders: A quantitative approach. PhD Thesis, Ghent University, Ghent.

Boussauw, K., T. Neutens, and F. Witlox. 2011. Minimum commuting distance as a spatial characteristic in a non-monocentric urban system : The case of Flanders. Papers in Regional Science 90 (1):47-65.

Boussauw, K., and F. Witlox. 2009. Introducing a commute-energy performance index for Flanders. Transportation Research Part A: Policy and Practice 43 (5):580591. 
CNC. 2010. Belgium's Greenhouse Gas Inventory (1990-2008). In National Inventory

Report. Brussels: Service Publique Fédéral Santé publique, Sécurité de la Chaîne alimentaire et Environnement.

Davoudi, S., J. Crawford, and A. Mehmood. 2009. Planning for climate change: strategies for mitigation and adaptation for spatial planners. Edited by $\mathrm{S}$. Davoudi, J. Crawford and A. Mehmood. London and Sterling, VA: Earthscan.

Ewing, R. H. 1994. Characteristics, causes, and effects of sprawl: A literature review. Environmental and Urban Studies 21 (2):1-15.

Hubert, J. P., and P. Toint. 2002. La mobilité quotidienne des Belges. Namur: Presses Universitaires de Namur.

Grosjean, B., 2010. Urbanisation sans urbanisme: Une histoire de la "ville diffuse", Mardaga, Belgium, 349 p.

IEA. 2010. World Energy Outlook. Paris: International Energy Agency.

IPCC. 2007. Climate change 2007: Mitigation of climate change. Summary for policymakers. Report of working group (WG) III to the fourth assessment report. Cambridge, UK.

IWEPS. 2008. Analyse des données des enquêtes régionales sur la mobilité des ménages en 2002 et 2004. DPDTM, Unpublished. Namur.

Kwan, M.-P., and J. Weber. 2008. Scale and accessibility: Implications for the analysis of land use-travel interaction. Applied Geography 28 (2): 110-123.

Marissal, P., L. P. Medina, C. Vandermotten, and G. Van Hamme. 2006. Les structures socio-économiques de l'espace belge. In Monographie $\mathrm{N}^{\circ} 6$. Bruxelles: SPF Economie, P.M.E., Classes moyennes et Energie. Direction générale Statistique et Information économique.

Newman, P., and J. Kenworthy. 1989. Cities and automobile dependence: An international sourcebook. Great Britain: Avebury Technical.

Pisarski, A. E. (2006) Commuting in America III. Washington, DC: Transportation Research Board.

Teller, J., S. Dujardin, F.-L. Labeeuw, E. Melin, and F. Pirart. 2010. Structuration du territoire pour répondre aux objectifs de réduction des émissions des gaz à effets 
de serre. In Colloque CPDT: La dimension territoriale des politiques énergétiques et de réduction des GES. Liège, Belgium.

Thomas, I., A. Verhetsel, and M. Beelen. 2008. Quand la Belgique se réveille. Les échos du logement 08: 34-40.

Van Acker, V., G. Allaert, K. Boussauw, E. Zwerts, and F. Witlox. 2011. Mobiel Vlaanderen in een mobiel Europa In De sociale staat van Vlaanderen 2011, edited by J. Noppe, L. Vanderleyden and M. Callens. Brussel Studiedienst van de Vlaamse Regering.

Verhetsel, A., I. Thomas, and M. Beelen. 2007. De kracht van het Alonso-Muth-Model. Het woon-werkverkeer in en rond de Belgische grootsteden. Ruimte en Planning 27 (3): 9-28.

Witlox, F. (2007) "Evaluating the reliability of reported distance data in urban travel behaviour analysis". Journal of Transport Geography 15 (3): 172-183.

World Resource Institute. 2009. Navigating the Numbers: Greenhouse Gas Data and International Climate Policy. Washington, DC: World Resources Institute.

Zwerts, E., and E. Nuyts. 2004. Onderzoek Verplaatsingsgedrag Vlaanderen 2000-2001. Brussels-Diepenbeek: Ministry of the Flemish Community. 